\title{
EVIDENCE FOR ECONOMIC CONVERGENCE IN THE EU: THE ANALYSIS OF PAST EU ENLARGEMENTS
}

\author{
Wadim STRIELKOWSKI ${ }^{\mathrm{a}, \mathrm{b}}$, Felix HÖSCHLE ${ }^{\mathrm{c}}$ \\ a. E. Cairnes School of Business and Economics, National University of Ireland, \\ Galway, Republic of Ireland \\ ${ }^{\mathrm{b}}$ Faculty of Social Sciences, Charles University in Prague \\ Smetanovo nabr. 6, Praha 1, 11001 Prague, Czech Republic \\ ${ }^{\mathrm{C}}$ Department of Economics, Ludwig-Maximilians-University Munich, \\ Schackstraße 4, 80539 Munich, Germany
}

Received 11 March 2013; accepted 11 December 2013

\begin{abstract}
This paper discusses the evidence of economic convergence in the European Union during the past several decades and consecutive EU enlargements. We cluster different member states of the European Union by groups representing countries that joined the EU together and analyze whether these clusters converge against each other. In addition, we analyse whether there is a convergence within different groups of countries. We employ real GDP per capita in its seasonally adjusted version as the measure of convergence. Our results reveal that there is not much evidence about the existence of economic convergence within the European Union.
\end{abstract}

Keywords: economic growth, convergence, gross domestic product, real gross domestic income, EU enlargement.

JEL Classification: E24, J30, O11, P24.

\section{Introduction}

This paper examines the existence of economic convergence across the different groups of EU member states over the last 15 years. Since the countries in question were joining the EU gradually over time, it makes sense to compare different groups of countries separately, depending on the date of their EU accession.

Corresponding author Wadim Strielkowski

E-mail: strielkowski@fsv.cuni.cz 
The history of EU enlargements dates back to the 1950s. In 1951, Belgium, France, Italy, Luxembourg, the Netherlands, and West Germany created the European Coal and Steel Community. In 1956, the Treaty of Rome was signed that expanded the community into the European Economic Community, thus establishing a customs union among the above mentioned countries. In 1973, Denmark, the United Kingdom and Ireland joined the European Communities. Greece joined in 1981, so did Portugal and Spain in 1986. East Germany joined the community after the fall of the Iron Curtain in 1990. In 1993, Finland, Austria and Sweden joined what since 1993 became known as the European Union. In 2004, the largest enlargement of the European Union so far took place with Cyprus, the Czech Republic, Estonia, Hungary, Latvia, Lithuania, Malta, Poland, Slovakia and Slovenia joining the European Union. In 2007 Romania and Bulgaria became the EU members in 2007 and the most recent addition was Croatia which joined the EU on the $1^{\text {st }}$ of July 2013 (however, the case of Croatia is not analysed in our paper). Thence, EU member state can be clustered into groups defined by the date when they joined the European Union. It seems interesting to examine the convergence within these clusters and between them. In addition, it might be worth examining whether there is an evidence of convergence within the European Union as a whole. In our paper, the convergence is analysed based on the real GDP per capita as per its seasonally adjusted version in accordance with the Eurostat's definition (see e.g. Linn 2003).

We group the countries by the date when they joined the European Union. This might potentially lead to the issues with regard to the structural homogeneity within the clusters. However, we are confident that this is not our case. This belief can be justified by several observations. First of all, the countries that joined the European Union together are usually similar with respect to their political and economic background. Second, the original EU was founded by the central and southern European countries with relatively strong industries. Third, the countries that joined the European Union on a later date are grouped neatly along geographic, political and economic factors, as one can see in the summary above.

The exercise similar to ours was conducted in the research literature by various researchers and encompassing various groups of countries (see e.g. Matkowski, Prochniak 2004; Jelnikar, Murmayer 2006; Radović 2009; Bonetto et al. 2009; Vojinovic et al. 2010; Tvrdoň, Skokan 2011; Baležentis et al. 2010; or Kim et al. 2011), however this is the first attempt to compare the groups of EU member states by their dates of accession using sigma convergence.

The traditional exogenous growth model introduced by Solow (1956) suggests that all countries should evolve towards some steady state level of per capita income. This is driven by diminishing returns of all investments. Once the steady state is reached, the per capita growth is solely determined by the rate of technological progress which is supposed to be exogenous and the same for all countries. This suggests that there should be convergence within the European Union, although it might not be caused by the economic implications of the EU existence. Romer (1990) studied the endogenous growth theory and introduced the new concept of growth which was now seen as subject to firms trying to innovate to gain monopoly rents. According to him, the firms' behaviour could only be influenced by policy. For example, one could argue that a firm has a bigger monopoly rent when it can sell its products in the whole European Union. This would cause higher incentives to innovate which would lead to higher growth. 
Jelnikar, Murmayer (2006) analysed whether there existed a conditional convergence between the countries that joined the European Union before 2004. They built their model based on a neo-classical growth model as suggested by Solow (1956). Their database consisted mainly of GDP per capita observations for various EU countries. They demonstrated a negative relation between initial level of GDP per capita and growth over the following decades (called "beta convergence" and defined by Barro (1991) and Barro, Sala-i-Martin (1992)). They also examined what Barro, Sala-i-Martin call "sigma convergence". Further, they took logarithms of the GDP per capita of different countries and then showed that the standard deviation for the different countries declined while finding strong evidence for beta and sigma convergence.

Crespo Cuaresma et al. (2008) used panel data techniques to examine the long-term effect of the European Union membership on economic growth of a given country. They found a significantly positive effect of the length of the membership on growth. They also found that the further a country is trailing economically, the stronger was the advantage of being a member of the European Union. Recently, the regressions that are based on the Bayesian model averaging approach (where the estimation results are averages over a large number of regressions) employed in the above-mentioned paper increased the popularity as the way of finding economic growth determinants (e.g. Crespo Cuaresma, Doppelhofer 2007; or Prochniak, Witkowski 2013). Vintrová $(2004,2005)$ examined the CEE countries on their path to the EU and analysed the alternative measures of economic convergence. Her results seem to show limited evidence for the existence of convergence for the countries in question.

Moreover, economic convergence and specifically sigma convergence in transition economies and countries seeking the EU membership was also analysed in the array of papers. Just to name the most important, we can refer the reader to Matkowski, Prochniak (2004, 2007), Prochniak (2006), Arbia et al. (2008), Young et al. (2008), Rapacki, Prochniak (2009), Vojinovic et al. (2010), Szeles (2011), Oplotnik et al. (2011), or Libman, Vinokurov (2012).

The rest of this paper is organized as follows: Section 1 introduces the concept of economic convergence. Section 2 outlines the methodological approach. Section 3 provides an analysis of convergence within the groups and between the groups of countries. Conclusions section closes the paper with overall conclusions and discussions.

\section{Concept of convergence in economic literature}

Convergence intuitively means that the difference between two or more variables over time decreases and becomes negligible - i.e. converges to zero. One can examine the process of convergence between several variables over time based on the development of a standard deviation (also called "variance") (see e.g. Doyle et al. 2001; Dobrinsky 2006). For any two variables, examining the existence of convergence would mean that one has to monitor the difference between these two variables. The next step would be to show that this measure does not converge or converges to zero. In order to examine the existence of convergence in the case of any two countries, the following inequality must hold true:

$$
|y 1, t-y 2, t|>|y 1, t+s-y 2, t+s|,
$$

where: $y 1, t$ and $y 2, t$ yield respective economic values of countries 1 and 2 in time $t$ and the convergence in question is measured as the difference between times $t$ and $t+s$. 
Absolute convergence resulting from the neoclassical growth model implies that countries with lower levels of real GDP per capita exhibit higher growth rates which cannot be attributed to other characteristics of their economies. This conclusion stems from the observation that there are higher rates of convergence to the same steady state in economies that are farther away. In the very simple model where technology is a constant (e.g. Cobb-Douglas production function $\left.Y(t)=K(t)^{\alpha}(A(t) L(t))^{1-\alpha}\right)$ the growth of income per capita in steady state is zero and the growth rate of income under this steady state is either positive or negative for lower (or higher) income levels than the corresponding steady state. For more complex model (Solow and Ramsey models can work with this production function) with the technology growing in time, the rate of growth of income per capita equals to the growth of technology and under constant condition might be higher or lower then this growth. In any case, the rate of approaching a steady state is an increasing function of output and output gap in a steady state (Barro 1991).

In the concept of conditional convergence the unrealistic assumption of constant and identical steady states for different states of the economy is lifted. This is due to the fact that the faster economies grow the greater is the difference between the output in steady state and desired output. Moreover, it is possible to find cases where countries with higher per capita income grow faster than countries with lower levels of income per capita. Therefore, convergence is preconditioned by the "controlling" of variables that cause different stable states (the rate of savings, parameters of production function, government policies affecting the location of production functions, etc.).

According to the logic of $\beta$-convergence, less wealthy countries (i.e. countries with lower income per capita) grow faster than more wealthy countries (see e.g. Vintrová 2005). The concept of $\beta$-convergence can be defined by the following regression equation:

$$
\log (y i, T)-\log (y i, 0)=\alpha 1-\beta 1^{\star} \log (y i, 0)+\varepsilon i,
$$

where: $i$ is the number of observation (a country), 0 and $T$ are time periods. $\beta$-convergence assumes the positive value of $\beta 1$. If all countries had the same steady state $\alpha 1$ and the time frame was long enough so all the countries could converge to it, $\beta 1$ would be equal to 1 .The coefficient $\beta 1$ yields how big is the difference that the countries would be able to eliminate respective to the steady state on average. Surely, we suppose that in the steady state the growth per capita equals to 0 .

The concept of $\delta$-convergence means reducing the level of "dispersion" income per capita (i.e. variance or standard deviation) between economies in a given period of time. To avoid the effect of random fluctuations which have only a transient effect between the time periods $t$ and $t+1, \delta$-convergence defines the following inequality:

$$
\delta_{t}^{2}>E\left[\delta_{t+1}^{2}\right]
$$

or, ex post, this can be written as:

$$
\delta_{t-1}^{2}>\delta_{t}^{2}
$$


Another important concept of convergence is the so called "club-convergence". Club-convergence, as defined for example by Monojit (1992), means that countries sharing certain characteristics converge towards each other. The shared characteristics are economic variables like saving rates or education standards.

\section{Methodological approach used in this study}

In order to estimate the convergence within the different groups of countries, one needs to calculate the standard deviation of the GDP per capita for each group. Convergence is achieved if the standard deviations decrease (Fig. 1). However, it has to be noted that only the sigma convergence concept is empirically tested in this study. The graphs in Figure 1 show the standard deviation within the predefined groups of countries. Therefore, it illustrates how convergence developed within the different groups. Small values indicate that convergence is relatively far advanced for a group of countries. However, it contains no information on how far convergence is advanced between the different groups. Therefore, a line representing a group of wealthier countries can lie below the line representing a group of less wealthy countries. The lines were generated by calculating the standard deviation with regard to the GDP per capita for each group of countries $i$ and for every period $t$.

$$
Y_{t}=\frac{1}{n} \sum_{i=1}^{n} I_{i t}-\bar{I}_{g t}
$$

where: $\bar{I}_{i t}$ is the average GDP per capita for group $g$ in year $t ; n$ represents the number of countries in each group; and $I_{i t}$ represents the GDP per capita of country $i$ in year $t$.

Figure 1 does not yield any obvious signs of convergence for any of the groups. The blue line on top of Figure 1 (founding EU Members) shows a relatively strong increase. This might be somewhat misleading, since the main driver behind this is a strong increase of the GDP

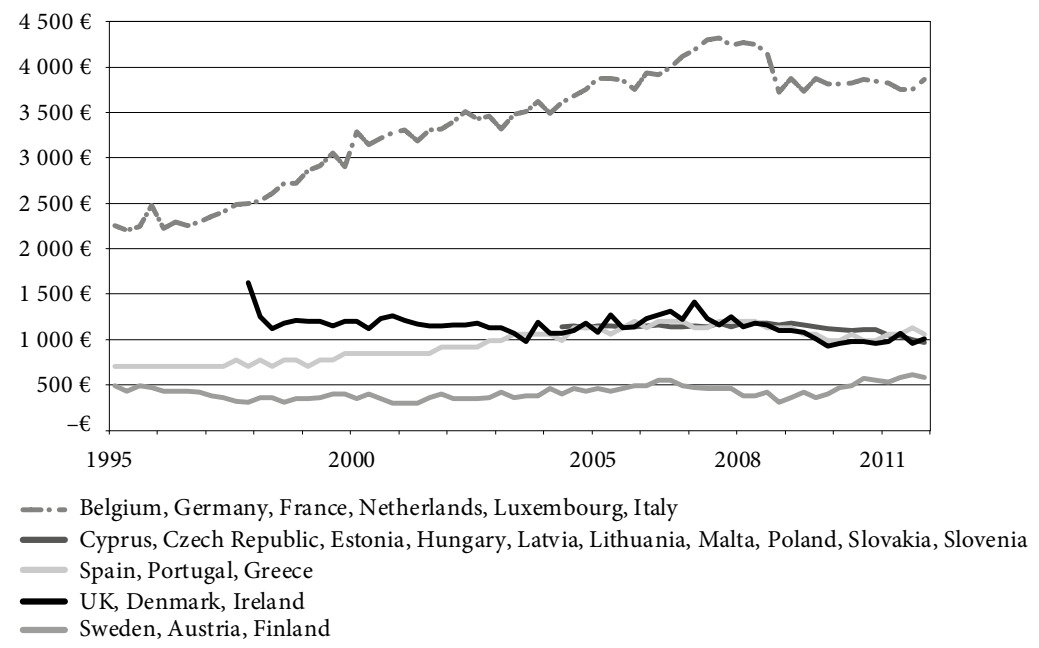

Fig. 1. Convergence within the groups of EU member states in terms of GDP per capita standard deviation Source: own results. 
per capita in Luxembourg. The Luxemburg observations skew the data, since Luxembourg has the same weight in the calculation of the standard deviation, while it is a very little country with a small population. Therefore, it is unreasonable to conclude that there is divergence within the founding members of the European Union from the results depicted on in Figure 1. The fact that Luxembourg is much wealthier than any other of the founding members of the European Union explains why the standard deviation in this group is so much higher than in any of the other groups. The rest of the lines in Figure 1 do not depict any significant change in any direction over the period in question. This suggests that there is no convergence within the groups that joined the European Union together. The general evidence of divergence does not refer fully to the CEE countries which converged, at least partly, during the transition period (the 1990s and the 2000s). Part of the reason for that might be that the countries differ within the groups that joined together. If countries have different structures in politics, society, economy, population size or similar factors they might also have different growth tracks. As a result of their varying starting conditions the countries are not going to take advantage of the new opportunities simultaneously. Thus, there would be no signs of convergence during the period under observation, while it is still to come in the future.

\section{Analysis of convergence: within the groups and between the groups of EU member state}

In order to examine the existence of convergence between different groups of countries (Figs 2-8), we first need to calculate the average GDP per capita for each group which also gives us the difference between the averages. If the difference in averages is declining, then there the convergence is detected.

Figures 2-8 somewhat differ from Figure 1, since they do not depict any standard deviations. Each of the figures contains three lines. In every figure there are two lines representing the GDP per capita for one of our predefined groups. The third line in every figure is generated by subtracting one of the two previous lines from another.

$$
Y_{t}=\left(I_{g t}-I_{g^{\prime} t}\right)
$$

where: $Y_{t}$ is the value of the third line; $I_{g t}$ is the GDP per capita in country group $g$; and $I_{g^{\prime} t}$ is the GDP per capita in country $g^{\prime}$.

We define six different groups of countries which would mean that we could potentially come up with 16 cases comparing two groups in each case. We compare the founding EU members with all the other groups, except Bulgaria and Romania, since there is too much data lacking and the two countries are the members of the EU for just a short period a time. Furthermore, we compare the countries that joined the EU after the Eastern enlargement in 2004 with the cluster embedding Spain, Portugal and Greece, since they were very similar conditions prior to the respective enlargement.

Furthermore, we compare the East enlargement countries with Sweden, Finland and Austria, since the difference in GDP per capita between them was one of the largest prior to the respective enlargement. Finally, we compare the cluster with the UK, Ireland and Denmark to the Southern European members that include Spain, Greece and Portugal. 
It has to be noted that also in this case there might be concern that differences between the countries in the groups with respect to politics, society, economy, population size or similar factors that might skew our results. Convergence might still be to come since different kinds of groups need to adapt to the new opportunities at their own speed. Another concern with respect to assessing the success of the EU enlargements might be time that passed since the different groups joined the EU. Nevertheless, it seems reasonable to assume that for the majority of groups of countries enough time has passed to assess the outcomes. Only in the case of the EU Eastern enlargement in 2004 there might be some debate whether this has actually happened although even in this case one can look back and reflect on almost a full decade of EU membership. This explains why Bulgaria and Romania are not part of our study due to their nature and duration of their membership in the European Union.

Our approach is complementary to the works of Crespo Cuaresma, Doppelhofer (2007) and Crespo Cuaresma et al. (2008) who use a panel data approach. Moreover, our approach leads to results that are relatively easy to analyse. Still, it should be viewed in the context of the work of other scholars on this topic.

Figure 3 demonstrates that the difference in GDP per capita for the EU founding members and Finland, Sweden and Austria, remained constant and relatively small. Subsequently, the trends for both groups are moving almost in parallel. This suggests that the economies of the different clusters were already highly integrated and operating on a similar level before 1995 .

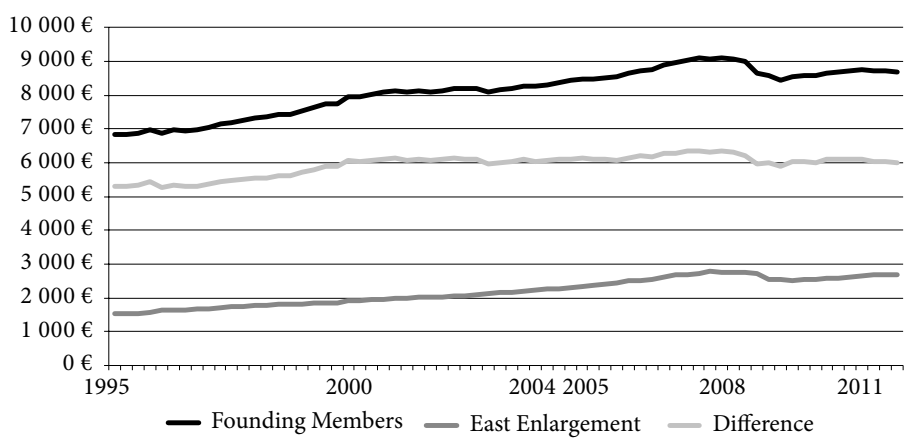

Fig. 2. Convergence in GDP per capita for the EU founding members vs. EU Eastern enlargement Source: own results.

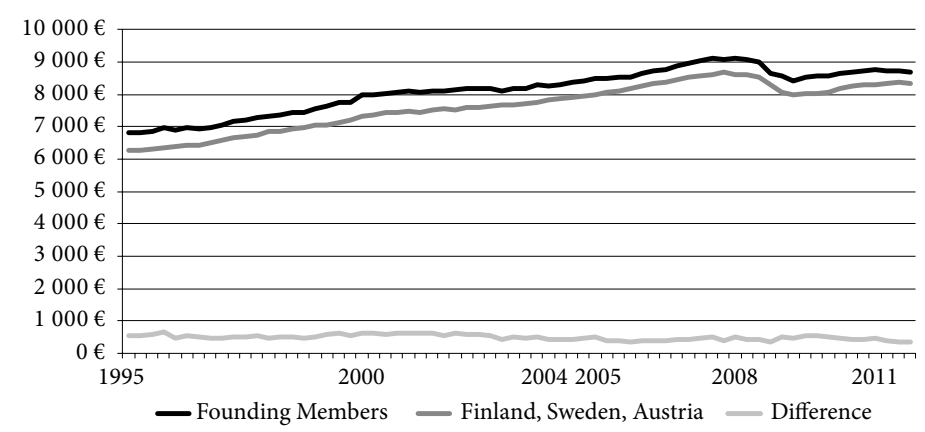

Fig. 3. Convergence in GDP per capita of EU founding members vs. Finland, Sweden and Austria Source: own results. 
Since Finland Sweden and Austria joined the European Union only a few years before the start of the time series that underlines the graph, it is quite possible that the economies already converged prior to their accession. However, it appears quite difficult to prove this assumption using the data obtained from Eurostat and therefore this issue might be subjected to further research and discussion.

The comparison between the founding members and the EU, UK, Ireland and Denmark yields similar results to the previous case (Fig. 4). Here, the case that the different groups of economies converged prior to 1995 comes through as even more significant, since the difference between the averages of the GDP per capita is very close to zero.

Due to the fact that very often this difference comes through as negative and sometimes as positive, one can argue that it is actually equal to zero and gets skewed by the white noise in the data (e.g. due to the cyclical phenomena).

Unlike the two previous cases, the results for the comparison between founding EU members and Spain, Portugal and Greece show somewhat different results (Fig. 5).

One can see two very different economies and witness the issue of convergence in the case of the EU founding members with an average GDP per capita about two times larger than the average of Spain, Portugal and Greece (Fig. 5). Looking at the graph for the difference one can hardly see any downwards trend. This might suggest that there was hardly any convergence between the groups of countries in question over the last 15 years.

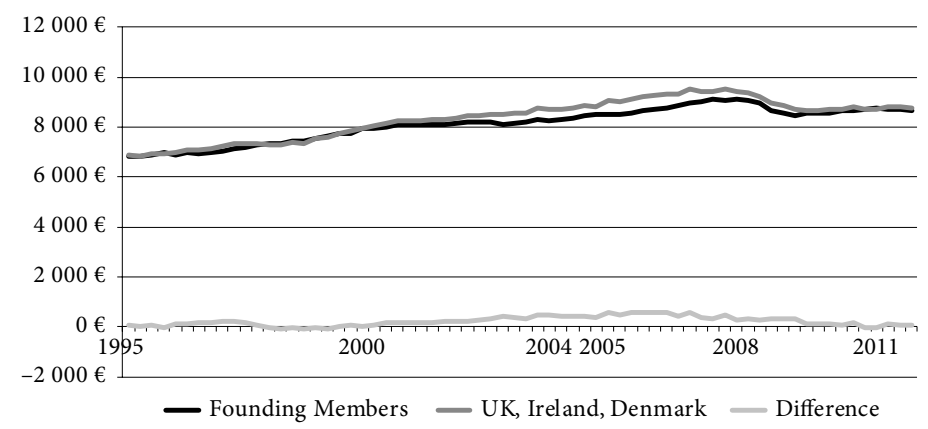

Fig. 4. Convergence in GDP per capita of EU founding members vs. UK, Ireland and Denmark Source: own results.

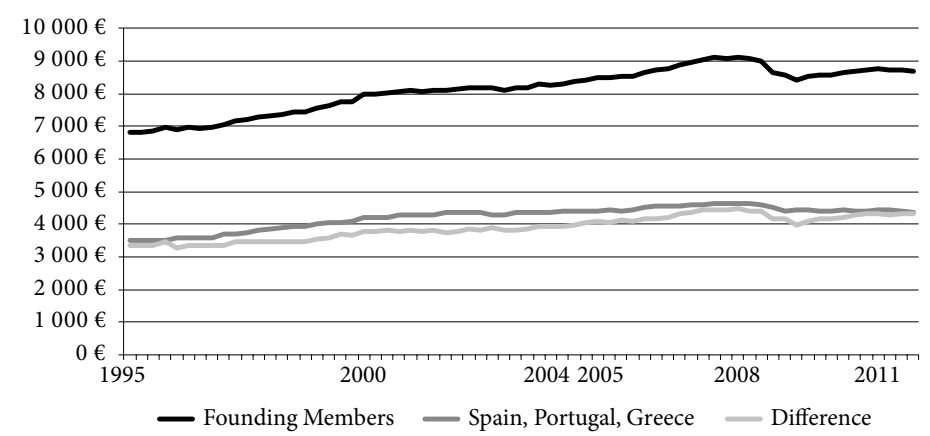

Fig. 5. Convergence in GDP per capita of EU founding members vs. Spain, Portugal and Greece Source: own results. 
Figure 6 shows that the difference between the averages in GDP per capita declines in the countries involved in the EU Southern enlargement and those involved in the Eastern enlargement. This decline starts shortly prior to the EU Eastern enlargement in 2004.

Nevertheless, one can easily observe a slow and steady convergence until the end of the timeline. The convergence had started before the financial crisis of 2008 and did not gain speed after the crisis was over. This might mean that it is probably not spurred by the recent trouble with the Southern European economies. Our results also seem to suggest that there is some convergence between the two groups since the EU enlargement.

The difference in GDP per capita between Sweden, Finland and Austria (Fig. 7) on the one side, and the countries of the Eastern enlargement of the EU, on the other side, remains more or less constant since 2004. While this finding does not directly suggest the existence of convergence, it breaks the divergence suggested by the graph prior to 2004 .

Figure 8 does not uncover any convergence in terms of GDP per capita between the two groups of countries in question (the first enlargement vs. the Southern enlargement). Instead, hat there was a slight divergence. Notably, the signs of divergence appeared after the financial crisis of 2008 that might be considered to be the noise itself.

Finally, we present the results of the standard deviation of the GDP per capita for the whole European Union. Since our dataset begins in 1995, we do our calculations in two consecutive steps. Firstly, we take the complete time period from 1995 to 2011 and leave out

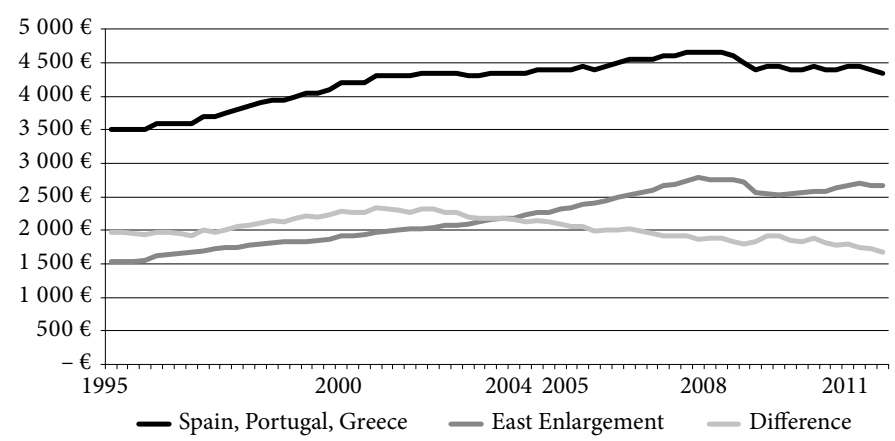

Fig. 6. Convergence in GDP per capita of EU Eastern enlargement countries vs. Spain, Greece and Portugal Source: own results.

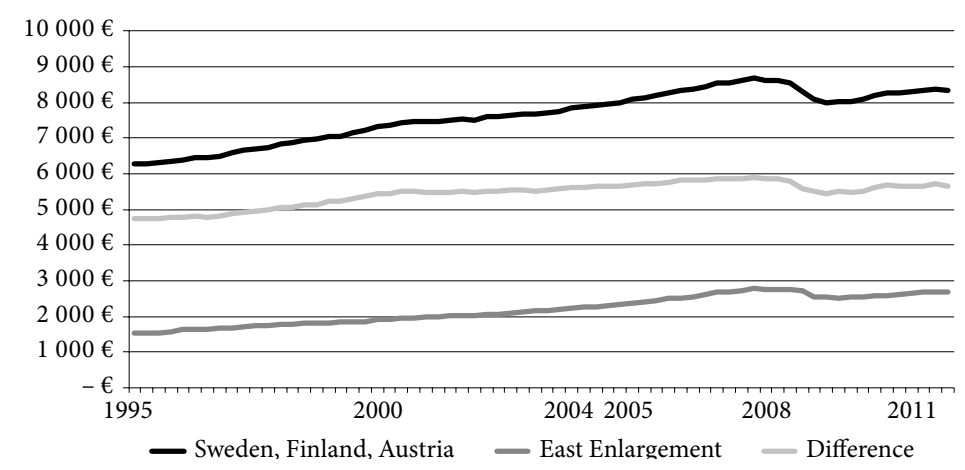

Fig. 7. Convergence in GDP per capita of EU Eastern enlargement vs. Finland, Sweden and Austria Source: own results. 


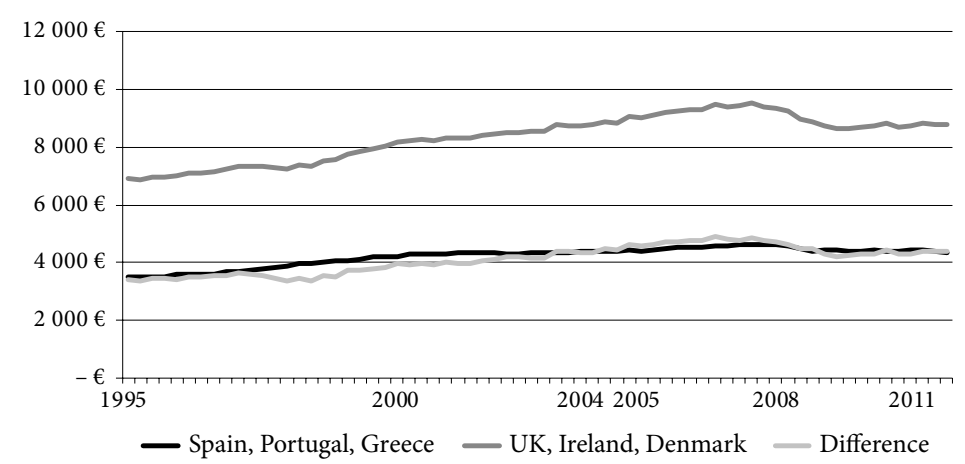

Fig. 8. Convergence in GDP per capita of UK, Ireland, Denmark vs. Spain, Greece and Portugal Source: own results.

the countries that belonged to the EU Eastern enlargement in 2004. Secondly, we use the data for the time period from 2005 to 2011 for all EU member states. The countries that joined the EU in 2007, Bulgaria and Romania, are excluded from both steps of our analysis since they joined the EU only recently and their effect might be marginal.

The respective lines in Figures 9 and 10 are created by taking standard derivations for the countries in the particular groups that are relevant to the figure:

$$
Y_{t g}=\frac{1}{n} \sum_{i=1}^{n} I_{n t}-\bar{I}_{g t}
$$

where: $\bar{I}_{i t}$ is the average GDP per capita for group $g$ in year $t$; $n$ presents the number of countries in each group and $I_{i t}$ represents the GDP per capita of country $i$ in year $t$.

The standard deviation of the GDP per capita for the countries that had been the members of the European Union prior to 2004 shows no signs of convergence until 2008 (Fig. 9).

The respective line in Figure 9 seems to rise over the given period of time, which suggests that there was a divergence present prior to the financial crisis of 2008. One can note a relatively sharp drop after 2008. After that there seems to be neither convergence, nor divergence.

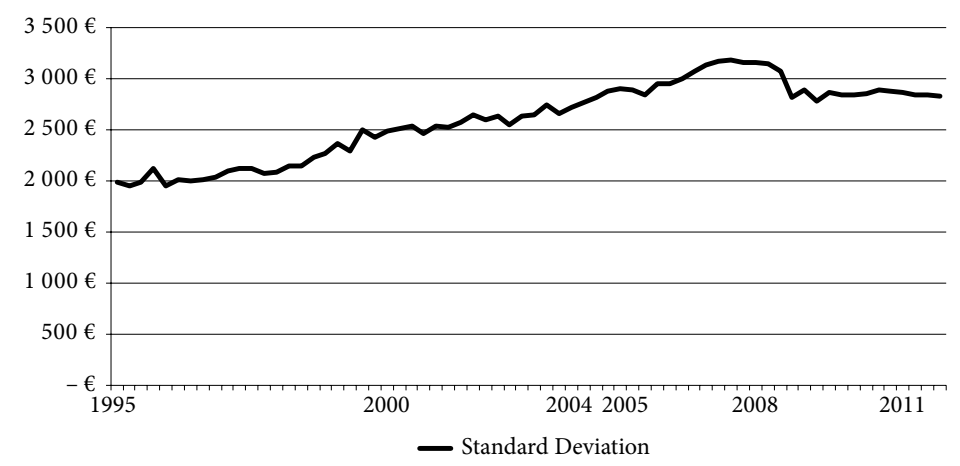

Fig. 9. Standard deviation of GDP per capita in the EU

(1995 to 2011, without EU Eastern enlargement countries, Bulgaria and Romania) Source: own results. 


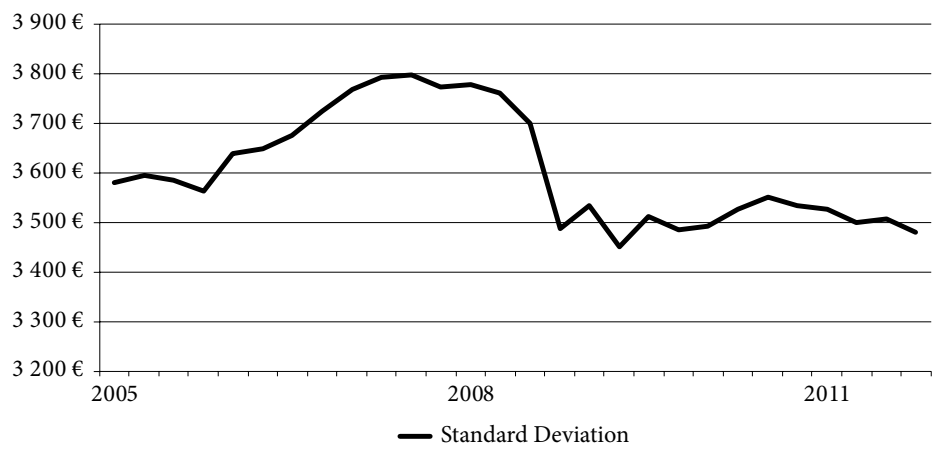

Fig. 10. Standard deviation of GDP per capita in the EU (2005 to 2011 with all countries except for Romania and Bulgaria) Source: own results.

Figure 10 covers a relatively short time period. Prior to the financial crisis of 2008, the line's shape suggests the presence of divergence.

However, after 2008 the line drops down below its initial level and remains relatively stable until the end of the time frame. Since our time frame was relatively small and there was mature noise due to the financial crisis, it appears impossible to state whether the graph suggests convergence or not.

\section{Conclusions}

Our analysis of available economic data for various EU countries and the groups of these countries shows very little evidence for convergence within the European Union (although it has to be noted that only the sigma convergence concept is tested in the study). We find that the countries that were EU Members prior to 2004 seemed to diverge instead of converging.

Assuming that the countries that joined together manifest groups that are relatively homogeneous, our results do not seem to support the concept of club-convergence. The concept of club-convergence would require that the countries that joined together converged against one another. Nevertheless, there is plenty of room for further research here, since it can be questioned whether these countries were really homogenous with respect to economic variables that were important for their growth. An analysis focusing more on conditional convergence could shed more light on this subject.

The standard deviation for all EU member states (without Bulgaria and Romania that were excluded from our analysis) declined. Still, it is hard to conclude that there actually was any convergence present due to the fact that the 2008 financial crisis accompanied by its asymmetric shocks in the different countries caused mature noise.

Looking at the different groups (or clusters) of countries under comparison, it is also hard to find strong evidence for convergence. This might be caused by the relatively small time frame covered by our data.

The founding members of the EU and the countries that have been EU members for a long time had likely converged to some extend prior to 1995. Especially in the case of the first three EU enlargements, one could observe the economies that operated on very similar 
levels and seemed to converge to a large extent. However, a brief look at the group of countries constituted the $2004 \mathrm{EU}$ enlargement reveals a somewhat different pattern. It appears that there is not much evidence for convergence against most of the other groups. The exceptions might be the strong convergence against Spain, Portugal and Greece since the EU Southern enlargement. Nevertheless, it might be too premature to make conclusions about the effects of the EU Eastern enlargement in the case of countries that joined the European Union in 2004.

Overall, our results do not show much evidence for the presence of convergence in the EU. This might be caused by the short time frame and the insufficient data, as well as the presence of the disturbances caused by the world's economic and financial crisis. Therefore, the fact whether the European Union spurs convergence between its members might need further research and in-depth analysis.

From a policy point of view this could lead to major questions for countries (e.g. Turkey or Serbia) that seek European Union membership. Most countries expect their economies to benefit from being a member of the European Union thanks to easier market access, transfer payments, factor and capital mobility. Yet, our results seem to be in favour of these expectations. Further research on similar topic yielding similar results might be reason for these countries to adjust their expectations for the EU accession and its possible outcomes.

There are various possible extensions to our research that could lead to further consequences for policy measures. It might be interesting to test the concept of convergence using different variables. For instance, our paper examines GDP per capita but other approaches might use an array of economic variables that measure economic well-being such as equality, life-expectancy, share of population below the poverty line, or the level of corruption. In addition, it would be possible to change the methodology employing other than panel data approach. These ramifications might bring more clarity to the question whether economic convergence happens in the EU within groups and between groups of member states that joined the EU in course of the same enlargements.

\section{References}

Arbia, G.; Le Gallo, J.; Piras, G. 2008. Does evidence on regional economic convergence depend on the estimation strategy? Outcomes from analysis of a set of NUTS2 EU regions, Spatial Economic Analysis 3(2): 209-224. http://dx.doi.org/10.1080/17421770801996664

Baležentis, A.; Baležentis, T.; Valkauskas, R. 2010. Evaluating situation of Lithuania in the European Union: structural indicators and multimoora method, Technological and Economic Development of Economy 16(4): 578-602. http://dx.doi.org/10.3846/tede.2010.36

Barro, R. 1991. Economic growth in a cross-section countries, Quarterly Journal of Economics 106(2): 407-443. http://dx.doi.org/10.2307/2937943

Barro, R.; Sala-i-Martin, X. 1992. Convergence, Journal of Political Economy 100(2): 223-251. http://dx.doi.org/10.1086/261816

Bonetto, F.; Redžepagić, S.; Tykhonenko, A. 2009. Balkan countries: catching up and their integration in the European financial system, Panoeconomicus 56(4): 475-489. http://dx.doi.org/10.2298/PAN0904475B

Crespo Cuaresma, J.; Doppelhofer, G. 2007. Nonlinearities in cross-country growth regressions: a Bayesian averaging of thresholds (BAT) approach, Journal of Macroeconomics 29(3): 541-554.

http://dx.doi.org/10.1016/j.jmacro.2007.03.001 
Crespo Cuaresma, J.; Ritzberger-Grünwald, D.; Silgoner, M. A. 2008. Growth, convergence and EU membership, Applied Economics 40(5): 643-656. http://dx.doi.org/10.1080/00036840600749524

Dobrinsky, R. 2006. Catch-up inflation and nominal convergence: the balancing act for new EU entrants, Economic Systems 30(4): 424-442. http://dx.doi.org/10.1016/j.ecosys.2006.07.008

Doyle, P.; Jiang, G.; Kuijs, L. 2001. Real convergence to EU income levels: Central Europe from 1990 to the long term. Volume 1. International Monetary Fund. 35 p.

Jelnikar, E.; Murmayer, U. 2006. Convergence in Europe: empirical analysis on two groups of countries of the European Union, in Proceedings of the Conference on Human and Economic Resources, co-organized by Izmir University of Economics and the State University of New York at Cortland, 24-25 May 2006, Izmir, Turkey, 246-260.

Kim, S. K.; Lee, B. G.; Park, B. S.; Oh, K. S. 2011. The effect of R\&D, technology commercialization capabilities and innovation performance, Technological and Economic Development of Economy 17(4): 563-578. http://dx.doi.org/10.3846/20294913.2011.603481

Libman, A.; Vinokurov, E. 2012. Regional integration and economic convergence in the Post-Soviet space: experience of the decade of growth, Journal of Common Market Studies 50(1): 112-128. http://dx.doi.org/10.1111/j.1468-5965.2011.02209.x

Linn, J. F. 2003. Economic (dis)integration matters - The Soviet collapse revisited, in Materials from the Conference on "Transition in the CIS: Achievements and Challenges" at the Academy for National Economy, 13-14 September 2004, Moscow, Russian Federation, 1-25.

Matkowski, Z.; Prochniak, M. 2004. Real economic convergence in the EU accession countries, International Journal of Applied Econometrics and Quantitative Studies 1(3): 5-38.

Matkowski, Z.; Prochniak, M. 2007. Economic convergence between the CEE-8 and the European Union, Eastern European Economics 45(1): 59-76. http://dx.doi.org/10.2753/EEE0012-8775450103

Monojit, C. 1992. Convergence clubs and endogenous growth, Oxford Review of Economic Policy 8(4): 57-69. http://dx.doi.org/10.1093/oxrep/8.4.57

Oplotnik, Z. J.; Vojinovic, B.; Acharya, S. 2011. Cross border economic convergence and EU integration process, Lex Localis - Journal of local self-government 9(2): 179-203.

Próchniak, M. 2006. Czynniki wzrostu gospodarczego-wnioski z badań empirycznych, Ekonomista 3: 305-345.

Prochniak, M.; Witkowski, B. 2013. Time stability of the beta convergence among EU countries: Bayesian model averaging perspective, Economic Modelling 30: 322-333.

http://dx.doi.org/10.1016/j.econmod.2012.08.031

Radović, I. 2009. Challenges for monetary policy in the enlarged European monetary union, Panoeconomicus 56(1): 95-110. http://dx.doi.org/10.2298/PAN0901095R

Rapacki, R.; Prochniak, M. 2009. Real beta and sigma convergence in 27 transition countries, 1990-2005, Post-Communist Economies 21(3): 307-326. http://dx.doi.org/10.1080/14631370903090616

Romer, P. 1990. Endogenous technological change, Journal of Political Economy 98(5): S71-S102. http://dx.doi.org/10.1086/261725

Solow, R. M. 1956. A contribution to the theory of economic growth, The Quarterly Journal of Economics 70(1): 65-94. http://dx.doi.org/10.2307/1884513

Szeles, M. R. 2011. Exploring the economic convergence in the EU's new member states by using non-parametric models, Romanian Journal of Economic Forecasting 14(1): 20-40.

Tvrdoň, M.; Skokan, K. 2011. Regional disparities and the ways of their measurement: the case of the Visegrad four countries, Technological and Economic Development of Economy 17(3): 501-518. http://dx.doi.org/10.3846/20294913.2011.603485 
Vintrová, R. 2004. The CEE countries on the way into the EU - adjustment problems, Europe-Asia Studies 56(4): 521-542. http://dx.doi.org/10.1080/0966813042000220458

Vintrová, R. 2005. What GDP Indicators do not tell you: alternative indicators of economic growth and real convergence, Czech Journal of Economics and Finance 11-12: 579-595.

Vojinovic, B.; Oplotnik, Z. J.; Prochniak, M. 2010. EU enlargement and real economic convergence, Post-Communist Economies 22(3): 303-322. http://dx.doi.org/10.1080/14631377.2010.498681

Young, A.; Higgins, M.; Levy, D. 2008. Sigma convergence versus beta convergence: evidence from US county-level data, Journal of Money, Credit and Banking 40(5): 1083-1093. http://dx.doi.org/10.1111/j.1538-4616.2008.00148.x

Wadim STRIELKOWSKI, PhD, is a Research Associate at J. E. Cairnes School of Business and Economics, National University of Ireland Galway, Galway, Republic of Ireland and an Assistant Professor at the Faculty of Social Sciences, Charles University in Prague, Czech Republic. He holds a PhD in Economics from the Charles University in Prague and a PhD in Economics of Regional Development from the National University of Ireland Galway. His research interests include economics of EU integration, international trade and finance, labour migration, as well as remittances and ODA.

Felix HÖSCHLE is a graduate student at the Department of Economics, Ludwig-Maximilians-University Munich, Germany. His research interests include international economics, macroeconomics, as well as international finance and business. 